\title{
Bend-Twist Coupling Characteristics Calculations of 5MW Wind Turbine Blades based on 3D Shell Model
}

\author{
Xingyin Zhou, Liqiang An, Zhangqi Wang and Hexiang Zhao
}

Mechanical Engineering Department, North China Electric Power University, Baoding, Hebei, China

Keyword: Bend-twist coupling; Shell method; Wind turbine blade.

\begin{abstract}
Five 5MW wind turbine blades with different ply orientation are modeled based on 3D shell element. The MPC method and a beam element are used in calculating their section stiffness. Bend-twist coupling parameters of the five models are calculated. Results show that section stiffness of wind turbine blade based on 3D shell model has higher efficiency and the accuracy of the method based on 3D shell model is verified.
\end{abstract}

\section{INSTRUCTION}

As a passive means to shape the power curve and reduce loads, bend-twist coupling blades are commonly researched. Researching related to bend-twist coupling blade in the 1990's are summarized in References [1] and pointed that the enough twist-bend coupling can reduce $10 \%$ of the fatigue load and improve energy capture. Reference [2] also confirm that bend-twist coupling blade using off-axis carbon in the skin will induce extra twist and alleviate load. Reference [3] design coupled blades where fibers are rotated only on the outboard part of blade and demonstrate this blade can achieve good load mitigation capabilities.

According to the slender structure characteristics of the blade, it usually can be simplified as beam model and bend-twist coupling parameter based on beam model is given in Reference [4], obviously, sectional properties are necessary to calculated based on this definition. Analytical method based on the classical laminated plate theory (CLP) in reference [5,6] has a higher efficiency while numerical method based on 2D finite element method in reference $[7,8]$ has a higher accuracy.

As a complex structure, blades are composed of several airfoils and made up of anisotropy material and 3D model of blades can more accurate and more truly covers the characteristics of the large blade. In this paper, the 5MW blades with different ply orientation are modeled based on 3D shell element and their section stiffness and bend-twist coupling parameters are calculated.

\section{THE FORMULA OF THE BEND- TWIST COUPLING}

Static equivalence of the wall stresses with the cross-sectional stress resultants produces the following equations relating the bending moment, $\mathrm{M}$, and torsion, $\mathrm{T}$, to the bending curvature $\mathrm{Kx}$, and rate of twist $\varphi z[5]$ :

$$
\left\{\begin{array}{c}
M \\
T
\end{array}\right\}=\left[\begin{array}{cc}
E I & -g \\
-g & G J
\end{array}\right]\left\{\begin{array}{c}
K_{x} \\
\varphi_{z}
\end{array}\right\}
$$

where, $E I$ is the bending stiffness, $G J$ is the torsional stiffness, and $g$ is the coupling stiffness. Then, $\alpha$ is defined as a parameter used to descript the level of bend- twist coupling,

$$
\alpha=\frac{g}{\sqrt{E I G J}}
$$

It can be seen from Eq. 2 that sectional stiffness must be calculated before bend- twist coupling is research. 


\section{RESEARCH METHOD OF BEND-TWIST COUPLING CHARACTERISTICS}

\subsection{Basic definition}

A 3D shell finite element model of blade is showed in Figure 1, where xyz is blade coordinate system, $\mathrm{x}$ is the edgewise direction which lies in the rotation plane; $\mathrm{y}$ is the flapwise direction which perpendicular to the rotation plane; $\mathrm{z}$ is the pitch axis, xoz plane is rotation plane. $(\mathrm{U}, \mathrm{V}, \mathrm{W})$ represent the translations of the cross section aerodynamic center , ( $\psi \mathrm{BxB}, \psi \mathrm{ByB}, \psi \mathrm{BzB})$ are cross section rotation. $(\mathrm{u}, \mathrm{v}, \mathrm{w})$ are the node displacement of blade shell mode, $(\mathrm{x}, \mathrm{y}, \mathrm{z})$ are the position of node.

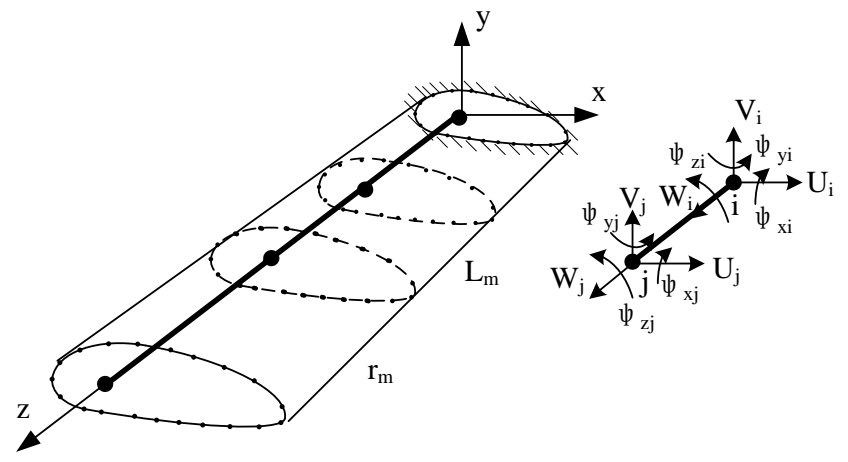

Figure 1. Blade coordinate system and forces and deformations of node

Assuming that, the cross section of blade will remain plane when the blade deforms, and shape remains unchanged, that is, ignoring inside and outside warp of plane.

\subsection{Node deformation of aerodynamic center}

With the plane assumption,

$\left\{\begin{array}{l}u=U-y \psi_{z} \\ v=V+x \psi_{z} \\ w=W+y \psi_{x}-x \psi_{y}\end{array}\right.$

denoted as,

$$
\left\{\begin{array}{l}
u \\
v \\
w
\end{array}\right\}=\left[\begin{array}{cccccc}
1 & 0 & 0 & 0 & 0 & -y \\
0 & 1 & 0 & 0 & 0 & x \\
0 & 0 & 1 & y & -x & 0
\end{array}\right]\left\{\begin{array}{c}
U \\
V \\
W \\
\psi_{x} \\
\psi_{y} \\
\psi_{z}
\end{array}\right\}
$$

In section that composed of $\mathrm{n}$ nodes,

$$
\left\{\begin{array}{c}
u_{1} \\
v_{1} \\
w_{1} \\
\vdots \\
u_{n} \\
v_{n} \\
w_{n}
\end{array}\right\}_{3 n \times 1}=\left[\begin{array}{cccccc}
1 & 0 & 0 & 0 & 0 & -y_{1} \\
0 & 1 & 0 & 0 & 0 & x_{1} \\
0 & 0 & 1 & y_{1} & -x_{1} & 0 \\
\vdots & \vdots & \vdots & \vdots & \vdots & \vdots \\
1 & 0 & 0 & 0 & 0 & -y_{n} \\
0 & 1 & 0 & 0 & 0 & x_{n} \\
0 & 0 & 1 & y_{n} & -x_{n} & 0
\end{array}\right]_{3 n \times 6} \quad\left\{\begin{array}{c}
U \\
V \\
W \\
\psi_{x} \\
\psi_{y} \\
\psi_{z}
\end{array}\right\}_{6 \times 1}
$$


Obviously, equations (5) are overdetermined because there are 3n equations and only six unknowns. A least squares solution in MATLAB can solve these equations.

\subsection{Stiffness matrix of beam element}

The forces $\mathrm{F}$ and deformations d of nodes is shown as,

$d=\left[\begin{array}{ll}d_{i}^{T} & d_{j}^{T}\end{array}\right]^{T}$

where, $d_{i}=\left\{\begin{array}{llllll}U_{i} & V_{i} & W_{i} & \psi_{x i} & \psi_{y i} & \psi_{z i}\end{array}\right\}^{T}$

$F=\left[\begin{array}{ll}F_{i}^{T} & F_{j}^{T}\end{array}\right]^{T}$

where,

$F_{i}=\left\{\begin{array}{llllll}F_{x i} & F_{y i} & F_{z i} & M_{x i} & M_{y i} & M_{z i}\end{array}\right\}^{T}$

The displacements and rotations of the $\mathrm{j}$ node relative to the i node for the six load case can be determined by:

$$
\begin{array}{ll}
\Delta U=U_{j}-U_{i}-L \psi_{y i} & \Delta \psi_{x}=\psi_{x j}-\psi_{x i} \\
\Delta V=V_{j}-V_{i}+L \psi_{x i} & \Delta \psi_{y}=\psi_{y j}-\psi_{y i} \\
\Delta W=W_{j}-W_{i} & \Delta \psi_{z}=\psi_{z j}-\psi_{z i}
\end{array}
$$

denoted as,

$\Delta d=\left\{\begin{array}{llllll}\Delta U & \Delta V & \Delta W & \Delta \psi_{x} & \Delta \psi_{y} & \Delta \psi_{z}\end{array}\right\}$

where $L_{m}$ is the length of element. Then a reduced $6 \times 6$ stiffness matrix $\mathrm{K}$ :

$F_{j}=K_{6 \times 6} \Delta d$

Then the solution for the $\mathrm{K}$ is obtained as

$K=F_{j} \Delta d^{-1}$

If we apply three unit forces and three moments on tip of the blade, Fj can be written as

$$
F_{j}=\left[\begin{array}{cccccc}
1 & 0 & 0 & 0 & 0 & 0 \\
0 & 1 & 0 & 0 & 0 & 0 \\
0 & 0 & 1 & 0 & 0 & 0 \\
0 & -r_{m} & 0 & 1 & 0 & 0 \\
r_{m} & 0 & 0 & 0 & 1 & 0 \\
0 & 0 & 0 & 0 & 0 & 1
\end{array}\right]
$$

where $r_{m}$ is the distance from the applied loads to the $m$ th element.

\subsection{Section stiffness matrix}

Section internal force is

$f=\left\lfloor\begin{array}{llllll}f_{x} & f_{y} & f_{z} & m_{x} & m_{y} & m_{z}\end{array}\right\rfloor$

Section strains is 
$\varepsilon=\left[\begin{array}{llllll}\varepsilon_{x} & \varepsilon_{y} & \varepsilon_{z} & K_{x} & K_{y} & K_{z}\end{array}\right]^{T}$

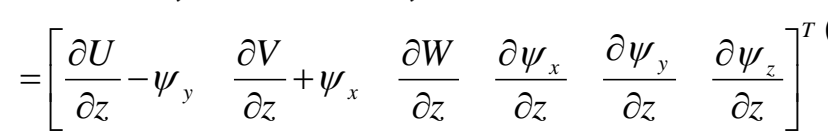

The constitutive matrix is

$f=k \varepsilon$ or $\varepsilon=k^{-1} f$

The relationship between beam element stiffness matrix and section stiffness matrix is,

$K^{-1}=k^{-1} B+\Gamma k^{-1} C$

where, $\Gamma$ is constant matrix ; $\mathrm{B}$ and $\mathrm{C}$ are variable matrix, as shown[9]

$B=\left[\begin{array}{cccccc}L & 0 & 0 & 0 & 0 & 0 \\ 0 & L & 0 & 0 & 0 & 0 \\ 0 & 0 & L & 0 & 0 & 0 \\ 0 & -\frac{L^{2}}{2} & 0 & L & 0 & 0 \\ \frac{L^{2}}{2} & 0 & 0 & 0 & L & 0 \\ 0 & 0 & 0 & 0 & 0 & L\end{array}\right]$,

$C=\left[\begin{array}{cccccc}\frac{L^{2}}{2} & 0 & 0 & 0 & 0 & 0 \\ 0 & \frac{L^{2}}{2} & 0 & 0 & 0 & 0 \\ 0 & 0 & \frac{L^{2}}{2} & 0 & 0 & 0 \\ 0 & -\frac{L^{2}}{3} & 0 & \frac{L^{2}}{2} & 0 & 0 \\ \frac{L^{2}}{3} & 0 & 0 & 0 & \frac{L^{2}}{2} & 0 \\ 0 & 0 & 0 & 0 & 0 & \frac{L^{2}}{2}\end{array}\right]$,

$\Gamma=\left[\begin{array}{cccccc}0 & 0 & 0 & 0 & 1 & 0 \\ 0 & 0 & 0 & -1 & 0 & 0 \\ 0 & 0 & 0 & 0 & 0 & 0 \\ 0 & 0 & 0 & 0 & 0 & 0 \\ 0 & 0 & 0 & 0 & 0 & 0 \\ 0 & 0 & 0 & 0 & 0 & 0\end{array}\right]$

The section stiffness matrix k can be determined by using Lyapunov’s method.

\section{TWIST-BEND COUPLING PROPERTIES OF A 5MW BLADE}

\subsection{Finite Element Model}

In this paper, a 5MW wind turbine blade is modeled which was developed at NREL by surveying the available conceptual designs in Reference[10] and WMC5MW ply and material information in Reference [11]. The 5MW blade consists of skin, spar cap and shear webs and the length of 5MW blade is $61.5 \mathrm{~m}$. The blade consists of eight different airfoils and has a maximum chord at about $20 \%$ 
spanwise direction, the maximum chord is $4.7 \mathrm{~m}$. Table 1 describes the breakdown of material usage in the 5MW blades [11]. The finite element model of a 5MW wind turbine blade is shown in Figure 2. SHELL99 element of ANSYS software is used in the model.

Table 1. Layer material properties

\begin{tabular}{l|l|l|l|l|l}
\hline & $\begin{array}{l}\text { uni- } \\
\text { direc- } \\
\text { tional } \\
\text { FRP }\end{array}$ & $\begin{array}{l}\text { double- } \\
\text { bias FRP }\end{array}$ & $\begin{array}{l}\text { Triaxial } \\
\text { FRP }\end{array}$ & $\begin{array}{l}\text { SKIN } \\
\text { FOAM }\end{array}$ & $\begin{array}{l}\text { WEB } \\
\text { FOAM }\end{array}$ \\
\hline $\mathrm{E}_{11} / \mathrm{GPa}$ & 38.89 & 24.8 & 11.7 & 0.256 & 0.025 \\
$\mathrm{E}_{22} / \mathrm{GPa}$ & 9.0 & 11.5 & 11.7 & 0.256 & 0.025 \\
$\mathrm{G}_{12} / \mathrm{GPa}$ & 3.6 & 4.861 & 9.77 & 0.022 & 0.012 \\
$\mathrm{v}_{12}$ & 0.249 & 0.416 & 0.501 & 0.3 & 0.3 \\
Density & 1869 & 1826 & 1782 & 200 & 45 \\
\hline$/(\mathrm{kg} / \mathrm{m} 3)$ & & \multicolumn{5}{|l}{} \\
\hline
\end{tabular}

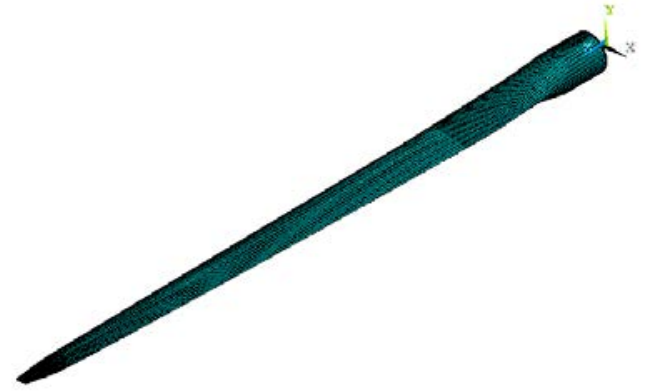

Figure 2. Finite element model of the 5MW blade

\subsection{Twist-bend Coupling Properties}

In order to weaken the influence of boundary effect on the calculation results in the process of computing stiffness, MPC184 and beam element are model at the tip of the blade. MPC184 element creates a link between a master node and a number of independent nodes of blade tip. The beam element creates a link between the master node and another node which used to apply load, as shown in Figure 3.

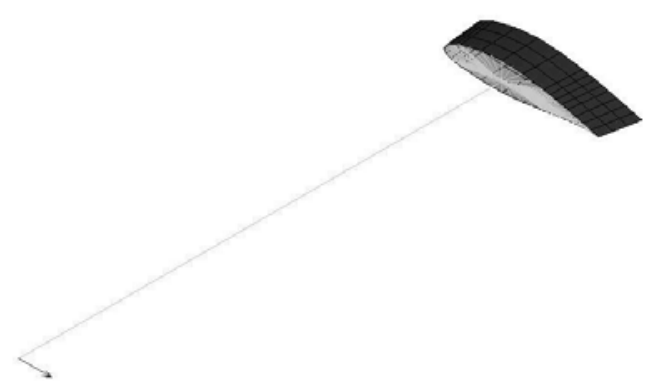

Figure 3. MPC element applied to the blade tip

Five blade models with different ply orientations are researched. They have the orientation of the layers of unidirectional fibers in the spar caps at angle of $10^{\circ}, 20^{\circ}, 30^{\circ}, 40^{\circ}$ and 500 . The coupling parameters of them are shown in Figure 4. 


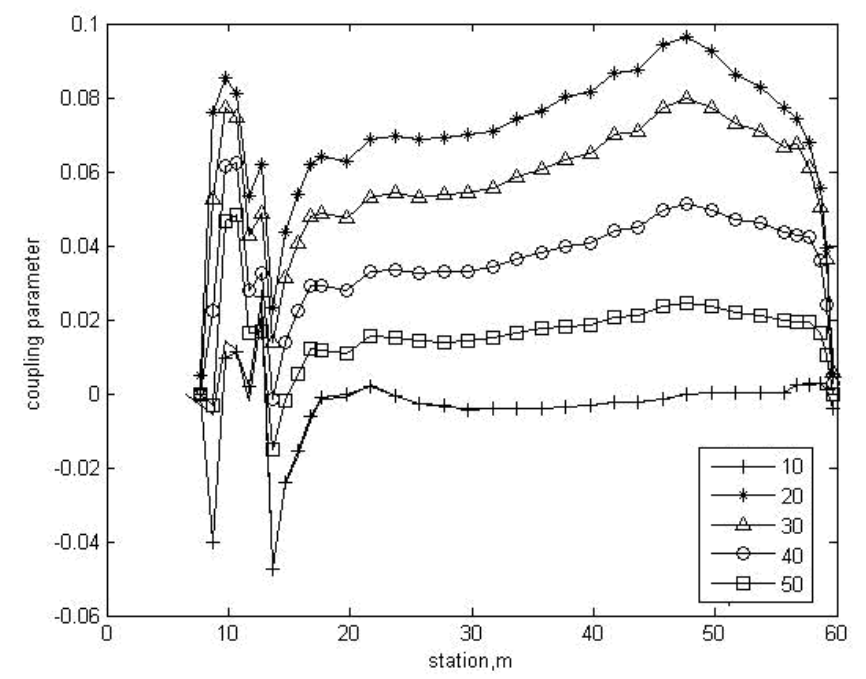

Figure 4. Coupling parameter

As shown in Figure 4, the 5MW wind turbine blade with 200 ply orientation has the maximum coupling parameter. This conclusion is the same as the Reference $[12,13]$ while the value of coupling parameters are different. The method based on shell mode has higher efficiency. The coupling parameter in blade root and transition region are irregular because the boundary effect of root and large gradient of geometric shape in transition region.

Section stiffness of the 5MW blade with 200 ply orientation are shown in Figure 5.

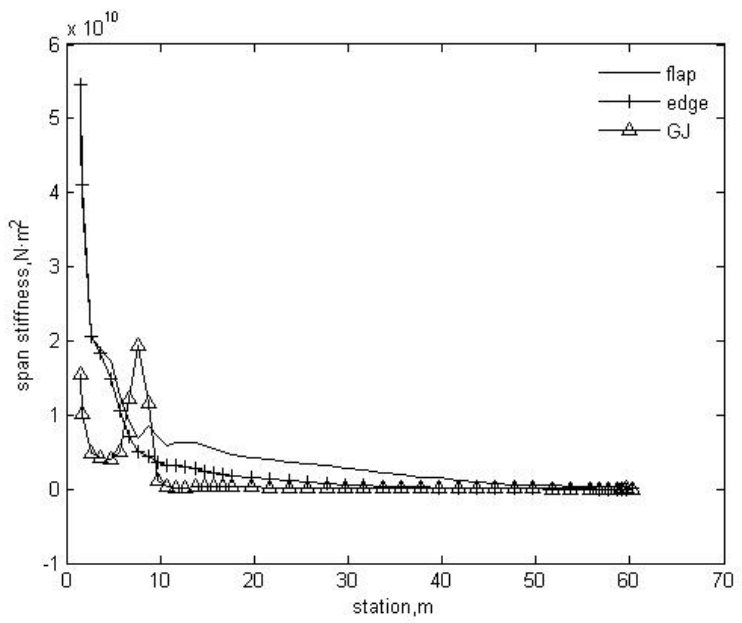

Figure 5. Section stiffness of the 5MW blade with 200 ply orientation

As shown in Figure 5, the stiffness decrease with the distance far away from blade root. Flapwise stiffness is the largest. Flapwise stiffness and edgewise stiffness are same at blade root because the round section. The torsional stiffness is irregular in transition region with the same reason as coupling parameter.

\section{CONCLUSION}

In this paper, five 5MW wind turbine blades are modeled using 3D shell element and their section stiffness and coupling parameters are calculated. The following conclusions are drawn.

(1) The section stiffness of wind turbine blade based on 3D shell model has higher efficiency than 2D finite element method of every section.

(2) The MPC method and a beam element are used to calculate section stiffness in order to weaken the influence of boundary effect. 


\section{ACKNOWLEDGEMENTS}

This research was supported by the Fundamental Research Funds for the Central Universities (13MS82, 2014ZD33) and Hebei Province Natural Science Foundation (E2013502291).

\section{REFERENCES}

[1] D.W. Lobitz, P.S. Veers, G.R. Eisler, D.J. Laino, P.G. Migliore and G. Bir. 2001. The Use of Twist-Coupled Blades to Enhance the Performance of Horizontal Axis Wind Turbines. Report SAND2001-1003, Sandia National Laboratories, Albuquerque, NM

[2] Thomas D.Ashwill. 2010. Passive Load Control for Large Wind Turbines. Report SAND20103276C, Sandia National Laboratories, Albuquerque, NM

[3] C.L. Bottasso, F. Campagnolo, A. Croce, C. Tibaldi. 2011. Optimization-Based Study of BendTwist Coupled Rotor Blades for Passive and Integrated Passive/Active Load Alleviation. 11,5

[4] D.W. Lobitz, D.J. Laino: 1999 ASME Wind Energy Symposium, 18th, Aerospace Sciences Meeting and Exhibit, 37th (Reno, NV, January 11-14,1999). p.125.

[5] Lin Wang, X.L.L.G. 2014. A mathematical model for calculating cross-sectional properties of modern wind turbine composite blades. Renewable Energy, 64: 52-60.

[6] Turaj Ashuri, M.Z.G.B. 2010. An Analytical Model to Extract Wind Turbine Blade Structural Properties for Optimization and Up-scaling Studies, in 3rd EWEA Conference - Torque 2010: The Science of making Torque from Wind., European Wind Energy Association. June 28-30,2010

[7] Blasques JP. 2011. Optimal design of laminated composite beams. Kgs. Lyngby : Technical University of Denmark.

[8] Wang Chunli. 2002. Profile properties research of composite blade for helicopter. Nanjing University of Aeronautics and Astronautics.

[9] David J. Malcolm, D.L.L., 2007. Extraction of Equivalent Beam Properties from Blade Models. Wind Energ.,10: 135-157.

[10] J Jonkman, S Butterfield, W Musial et al. 2009. "Definition of a 5 MW reference wind turbine for offshore system development”, National Renewable Energy Laboratory.

[11] R Nijssen, G D de Winkel, J M Peeringa. 2007. "WMC 5MW laminate lay-out of reference blade for WP3”. Knowledge Centre Wind turbine Materials and Constructions.

[12] ZHOU Xingyin, AN Liqiang, WANG Zhangqi. 2012,Twist-bend Coupling Analysis for 5MW Wind Turbine Blades[J]. AppliedMechanicsandMaterials, 152/153/154:703-708.

[13] C.H. Ong, S.W. Tsai. 1999. Design, Manufacture and Testing of a Bend-Twist D-Spar, Report SAND99-1324, Sandia National Laboratories, Albuquerque, NM 